\title{
Pharmacokinetics of RIF in patients with newly diagnosed, pulmonary tuberculosis. Comparison with pharmacokinetics in healty subjects
}

\author{
CRISTINA MIHAELA GHICIUC ${ }^{1}$, ROXANA SANDULOVICI ${ }^{2 *}$, CONSTANTIN \\ MIRCIOIU $^{3}$, VALENTINA ANUTA ${ }^{3}$, ION MIRCIOIU ${ }^{2}$
}

1“Gr. T. Popa” University of Medicine and Pharmacy 16 Universitatii Str., 700115 Iasi, Romania

${ }^{2}$ Titu Maiorescu University, Faculty of Pharmacy, Bucharest, Romania

3“Carol Davila" University of Medicine and Pharmacy, Faculty of Pharmacy, 6 Traian Vuia Str., 020956, Bucharest, Romania

\begin{abstract}
Rifampicin pharmacokinetics was evaluated in patients with newly diagnosed, untreated pulmonary tuberculosis after a single oral dose of $300 \mathrm{mg}$ rifampicin. Pharmacokinetic data in healthy volunteers were measured after oral administration of a single-dose, $2 \times 150 \mathrm{mg}$ tablets, in a randomized, two-treatments, two-periods, two-sequences cross-over bioequivalence study. Both experiments were performed in fasting conditions. method.

Within 24 hours after drug administration, 11 blood samples were collected and analysed by a validated HPLC

Non-compartmental analysis and compartmental modelling were performed by means of Kinetica software, version 3.1. Comparisons of the performances of compartmental models were established using Akaike and Schwarz criteria. Significance of differences between values of criteria was tested using F-test. Since the two compared formulations (reference and tested drug) proved to be bioequivalent in healthy subjects, pooling both sets of individual curves in a single "healthy subjects" set was considered justified.

Curves corresponding to patients were uniformly distributed within a wide concentration range, proving a significant inter-subject variability. Visual examination of the set of revealed a division into two clusters, one with maximum concentrations between $0.5 \mu \mathrm{g} / \mathrm{ml}$ and $1 \mu \mathrm{g} / \mathrm{ml}$ and another with maximum concentrations in the $2 \mu \mathrm{g} / \mathrm{ml}-$ $5 \mu \mathrm{g} / \mathrm{ml}$ range. Curves corresponding to healthy subjects appeared to be approximately normally distributed with a tail toward high concentrations.

Comparison of pharmacokinetic parameters revealed a series of significant differences between healthy subjects and patients. $\mathrm{C}_{\max }$ and areas under curve remained less than half for patients in comparison with healthy subjects.

Pharmacokinetic model which described the evolution of plasma levels of both healthy subjects and patients was the monocompartmental one. Fitting of the experimental data by means of the selected model appeared to be very good for healthy subjects. In the case of tuberculosis patients, fitting failed to describe the final part of the concentration-time curve, the elimination being slower than predicted by the model.

Examination of mean curves allowed a more refined analysis of the differences between plasma level curves of patients and healthy subjects. Final parts of mean curves $(12 h-24 h)$ for healthy subjects and patients were practically superposed. Differences appeared in the time interval from $\mathrm{T}_{\max }$ and 12 hours, following differences in distribution and metabolization phases. In conclusion suggests the necessity of increasing doses at the beginning of treatment, until a loading of compartments and saturation of the elimination processes.
\end{abstract}

Keywords RIF, pharmacokinetics, tuberculosis patients, healthy subjects, compartmental modelling.

To cite this article: GHICIUC CM, SANDULOVICI R, MIRCIOIU C, ANUTA V, MIRCIOIU I. Pharmacokinetics of RIF in patients with newly diagnosed, pulmonary tuberculosis. Comparison with pharmacokinetics in healty subjects. Rom Biotechnol Lett. 2020; 25(1): 1296-1303. DOI: $10.25083 / \mathrm{rbl} / 25.1 / 1296.1303$ 


\section{Introduction}

Rifampicin (RIF) is an essential component of firstline tuberculosis (TB) pharmacotherapy (BRAYFIELD, 2017). Its antimycobacterial utility against Mycobacterium tuberculosis infections is characterized by high sterilizing activity (i.e., high ability to eliminate semi dormant or persisting organisms in TB lesions). In addition, it prevents the emergence of resistance to its associated drugs.

High variability of therapeutic effect for RIF represents an important problem in therapy, with a lot of effects on both therapeutic outcome and associated cost of health insurance (RAFIQ, 2010; RAMAKRISHNAN, 2008; SUDFELD, 2013).

Clinical pharmacokinetic of RIF is largely analysed in the literature (MEDELLÍN-GARIBAY, 2015; MILANSEGOVIA, 2010; PÄHKLA, 1999; ZWOLSKA, 2002). RIF is metabolized mainly in the liver by various cytochrome-P450 (CYP) enzymes (GLAESER, 2005), and presents a low hepatic clearance and a bioavailability of 93-95\% (AGRAWAL, 2005; SVENSSON, 2018).

Peak serum levels are attained within 2-4 hours and vary widely from individual to individual (REQUENAMENDEZ, 2019). After a single oral dose of $600 \mathrm{mg}$, the peak level averages $7 \mu \mathrm{g} / \mathrm{mL}$ but may vary from 4 to $32 \mu \mathrm{g} / \mathrm{mL}$ (SEIJGER, 2019). Concomitant intake of food alters the rate and extent of absorption (PANCHAGNULA, 2003; PELOQUIN, 1999; ZENT, 1995).

RIF is about $85 \%$ protein bound (ABULFATHI, 2019), mostly to albumin. It is distributed into most body tissues and fluids including lungs, liver, bone, saliva, and peritoneal and pleural fluids. It penetrates inflamed meninges, crosses the placenta and is distributed into breast milk (STOTT, 2018). The drug is extensively metabolized in the liver to an active metabolite, 25-desacetylrifampicin, via deacetylation. The parent compound and its metabolite are primarily excreted $(60 \%)$ in feces via biliary elimination. Up to $30 \%$ of a dose is excreted in urine (SENG, 2015). The parent drug undergoes enterohepatic circulation with significant reabsorption. During this process, RIF undergoes progressive deacetylation.

Lower levels of RIF were obtained in patients after repeated dose administration, due to autoinduction of metabolism (MCILLERON, 2006).

The elimination half-life has been reported to range initially from 3-5 hours, but decreases with prolonged use due to increased biliary excretion resulting in half-lives of about 2 to 3 hours. About $60 \%$ of the dose is eliminated trough in the faeces. The antibiotic shows dose-dependent elimination kinetics. At higher doses, when the biliary route is saturated, the proportion of the dose excreted in the urine and the elimination half-life increases (ELLARD, 1999; SVENSSON, 2018). With dose of the order of $450 \mathrm{mg}$ and higher, the excretory capacity of the liver for the antibiotic is saturated. As a consequence, increasing the dose of antibiotic results in a more than proportional increase in serum concentrations (PARGAL, 2001).

Coefficient of variation of $43 \%$ for volume of distribution was demonstrated (WILKINS, 2008), whereas inter-occasional variability for serum clearance was $23 \%$ and mean transit time during absorption was $68 \%$.
The aim of this paper was to compare and investigate possible differences in pharmacokinetics of RIF after oral administration in newly diagnosed patients with tuberculosis and healthy subjects.

\section{Materials and Methods}

Study design. Rifampicin pharmacokinetics in TB patients was studied after administration of a single-dose of $300 \mathrm{mg}$ of RIF, under fasting conditions, to 6 newly diagnosed and untreated pulmonary TB patients.

Venous blood samples (approximately $10 \mathrm{~mL}$ ) were collected through a catheter inserted in an antecubital vein, pre-dose (0 hours) and at 0.5, 1.0, 1.5, 2.0, 2.5, 3.0, 4.0, 6.0, 8.0, 12.0, 18.0 and 21.0 hours after the drug administration. The diagnosis of pulmonary TB was based on clinical symptoms and chest X-ray examination and confirmed by microscopic detection of acid-fast bacilli.

RIF pharmacokinetics in healthy volunteers was studied after a single-dose administration, randomized, two-treatments, two-periods, two-sequence cross-over bioequivalence trial comparing equal doses (300 mg) of test and reference products, as previously described (MARCHIDANU, 2013).

The studies were conducted according to the principles of Declaration of Helsinki (1964) and its amendments and Good Clinical Practice (GCP) rules. The clinical protocols were reviewed and approved by an independent Ethics Committee and by the National Medicine Agency. All volunteers gave their written informed consent prior to inclusion in study.

Plasma levels of RIF were determined by using a validated HPLC method (FDA, 2001), with UV detection at $331 \mathrm{~nm}$.

Pharmacokinetic analysis. Pharmacokinetic analysis was performed using both compartmental and noncompartmental methods. Estimation of pharmacokinetic parameters was performed using subroutines of the KINETICA 3.1 software (Innaphase Corp, Philadelphia, PA, USA). Pharmacokinetic parameters were determined directly from plasma levels or by interpolation/ integration of theoretical models.

Compartmental analysis was performed using TOPFIT 2.0 software (Thomae GmbH, Germany). For hierarchisation of models' fitting performances, the Akaike and Schwarz criteria (both based on the sum of squared "errors" (SS) corrected by a "penalty" function proportional to the number of parameters $\mathrm{p}$ in the model (SANDULOVICI, 2009):

$$
\begin{aligned}
& \mathrm{AIC}=\mathrm{N} \ln \mathrm{SS}+2 \mathrm{p} ; \\
& \mathrm{SC}=\mathrm{N} \ln \mathrm{SS}+\mathrm{p} \ln \mathrm{N},
\end{aligned}
$$

where $\mathrm{N}$ is the number of points, in conjunction with phenomenological criteria. Significance of differences between values of criteria was tested using F-test.

\section{Results}

Comparison of populations of individual curves. Figure 1 shows individual plasma levels for healthy volunteers and patients. 


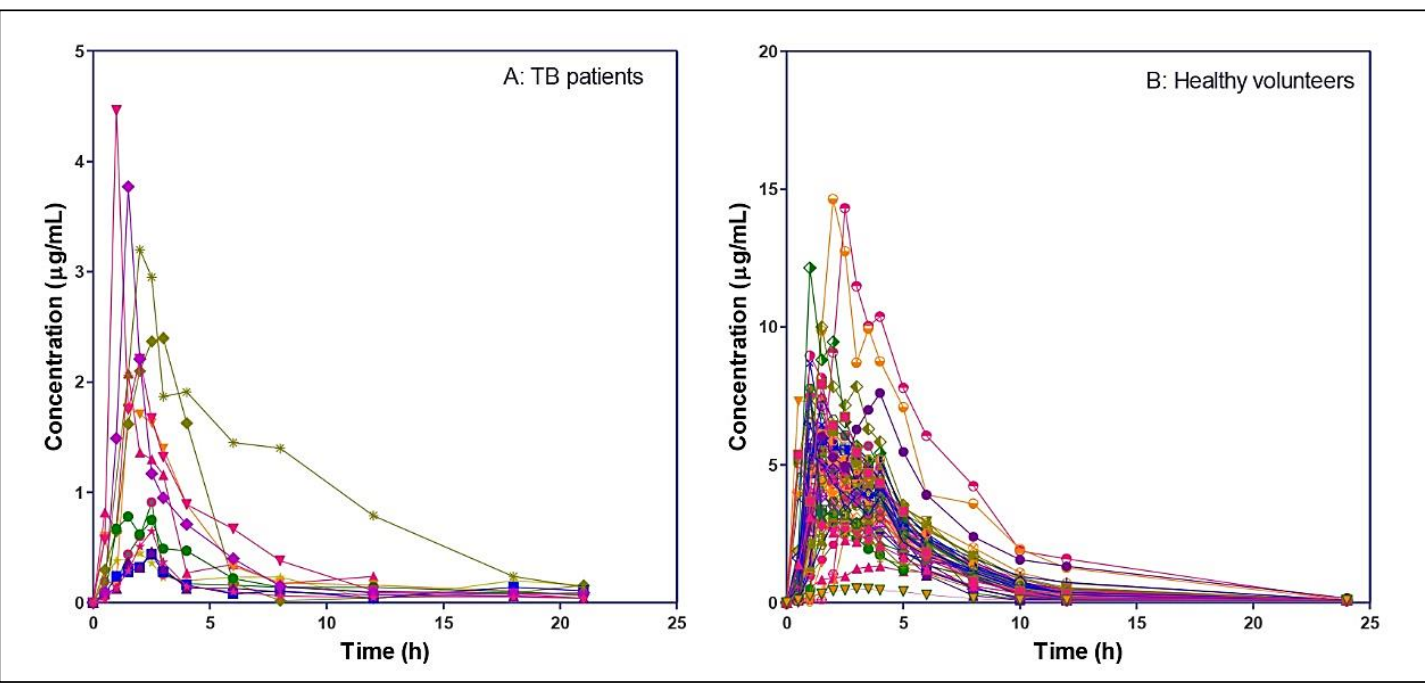

Figure 1. The individual pharmacokinetic profiles for RIF, after oral administration to TB patients (A, dose $=300 \mathrm{mg}, \mathrm{n}=12$ subjects) and healthy volunteers ( $\mathrm{B}$, dose $=300 \mathrm{mg}, \mathrm{n}=54$ subjects).

In almost all cases, both for healthy volunteers and patients, maximum concentrations were above $1 \mu \mathrm{g} / \mathrm{ml}$, which is considered threshold value for the appearance of therapeutic effect. But this level is maintained less than three hours and some curves are situated entirely under this value.

Curves corresponding to patients were distributed within a wide concentration range, proving a great intervariability. A division into two clusters, one with maximum concentrations between $0.5 \mu \mathrm{g} / \mathrm{ml}$ and $1 \mu \mathrm{g} / \mathrm{ml}$ and another with maximum concentrations in the $2 \mu \mathrm{g} / \mathrm{ml}-5 \mu \mathrm{g} / \mathrm{ml}$ range is a possible interpretation. Population of curves of healthy volunteers suggests a division into three clusters.
Non-compartmental analysis of the two formulations (reference $\mathrm{R}$ and tested drug $\mathrm{T}$ ) in the case of healthy volunteers (Figure 2) led to an approximately normal distribution of the pharmacokinetic parameters area under curve (AUC) and $\mathrm{C}_{\max }$, with a "tailing" trend towards greater values. Distributions were similar for the two treatments. Since additionally, the products were bioequivalent, it was considered justified to pool the both sets of individual curves in a single "healthy volunteers" set. 54 pharmacokinetic curves were obtained, a sufficient number to reliable estimate the range and variability of population of plasma levels in healthy subjects.

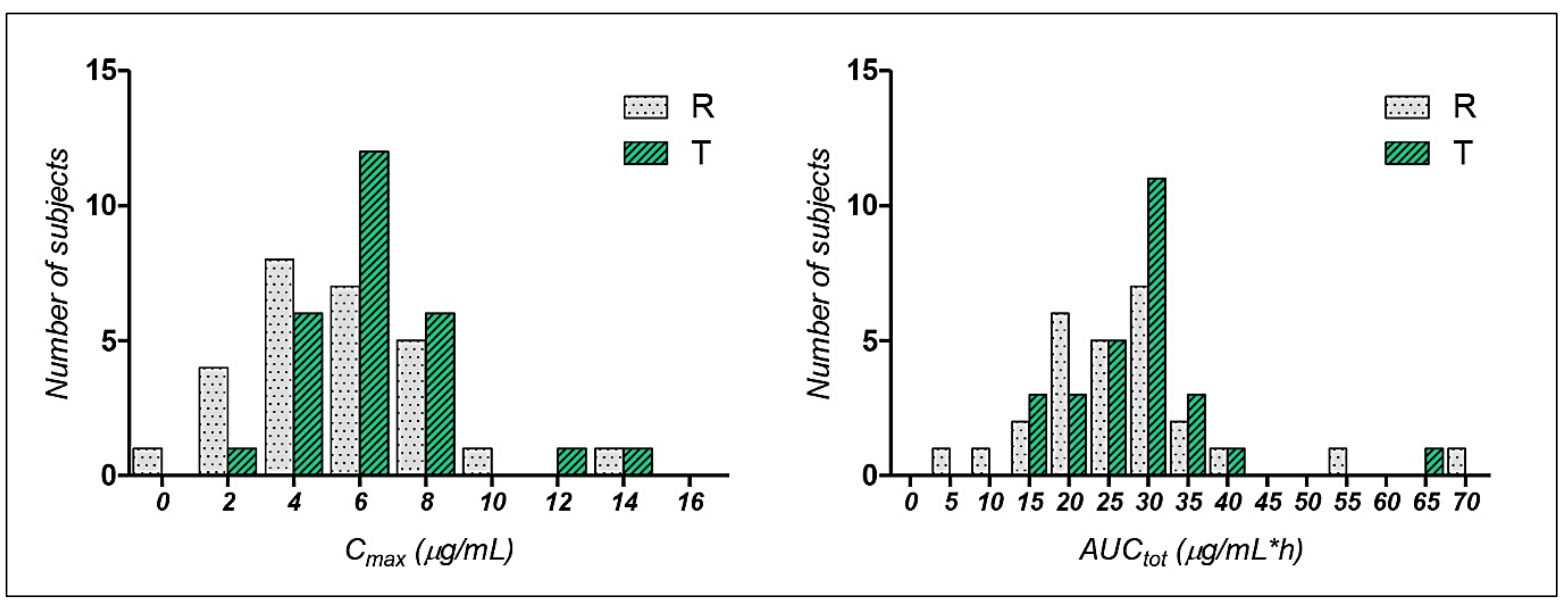

Figure 2. Distributions of pharmacokinetic parameters of reference and tested drugs, a. $C_{\max }$, b. $A U C_{t o t}$

Comparison of estimated pharmacokinetic parameters of healthy volunteers and patients

Distribution of the main pharmacokinetic parameters $\mathrm{AUC}_{\text {tot }}$ and $\mathrm{C}_{\max }$ for healthy volunteers, obtained by noncompartmental analysis (pooled $\mathrm{R}$ and $\mathrm{T}$ ) are presented in
Figure 3 (B). If maximum concentrations $\left(\mathrm{C}_{\max }\right)$ appears to be approximately normally distributed, in case of exposure $\left(\mathrm{AUC}_{\mathrm{tot}}\right)$ distribution is asymmetric, with a tail in the upper value range, as was suggested by examination of the curves. 


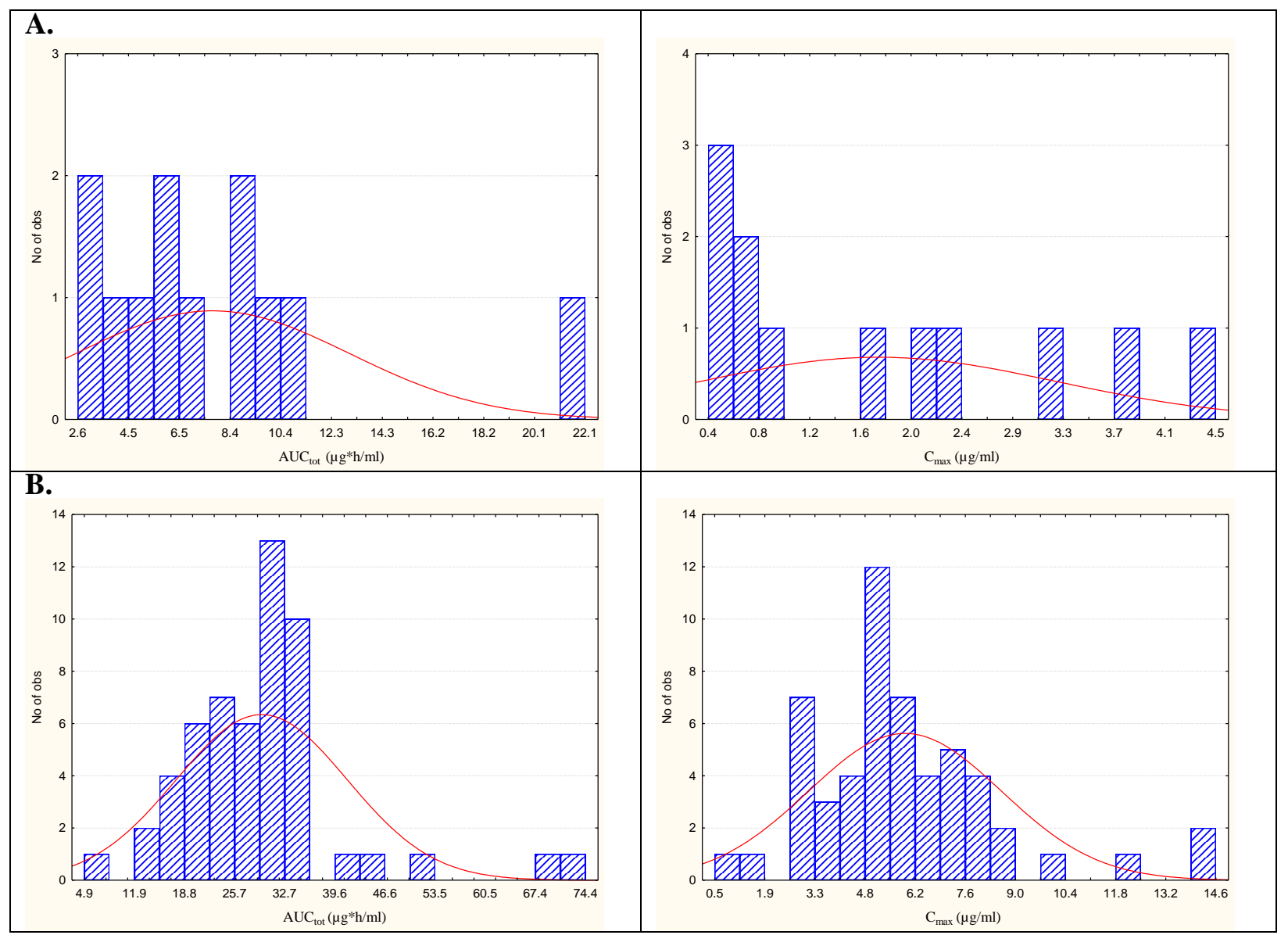

Figure 3. Frequency distribution pattern of $\mathrm{AUC}_{\mathrm{tot}}$ and $\mathrm{C}_{\max }$ for RIF after oral administration to TB patients (A) and healthy volunteers $(\mathbf{B})$.

In case of frequency distribution pattern of $\mathrm{AUC}_{\text {tot }}$ for TB patients (Figure 3A, applying criteria for defining an outlier (MIRCIOIU, 2010) in AUC population, one subject appeared to be outlier (an $\mathrm{AUC}_{\text {tot }}$ double than the next value). Data concerning $\mathrm{C}_{\max }$ are asymmetric, with a long tail toward high values.

\section{Comparison of mean plasma level curves}

Examination of mean curves confirms the global analysis made on individual curves: bioavailability of RIF in TB patients is less than half of that in healthy subjects (Figure 4).

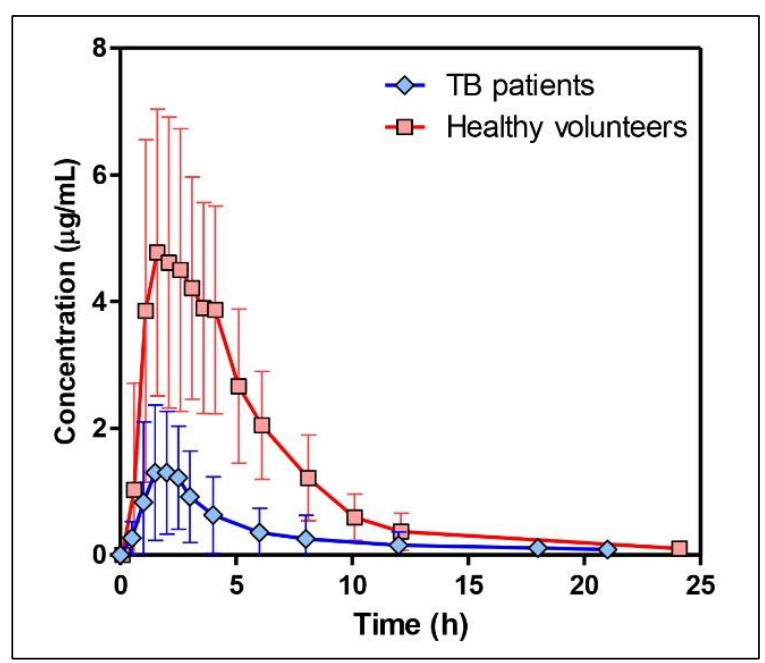

Figure 4. Mean plasma levels of RIF after oral administration to healthy volunteers $(n=54)$ and TB patients $(n=12)$. 
Compartmental analysis. In order for a more in-depth exploration of the pattern of these differences, an analysis of data using compartmental models was undertaken. The pharmacokinetic model that better described the evolution of plasma levels of both healthy subjects and patients was the monocompartmental one. Fitting appeared to be very good in case of healthy subjects (Figure 5). In case of the patients, fitting failed in the final part of curve, the elimination being slower than predicted by model.

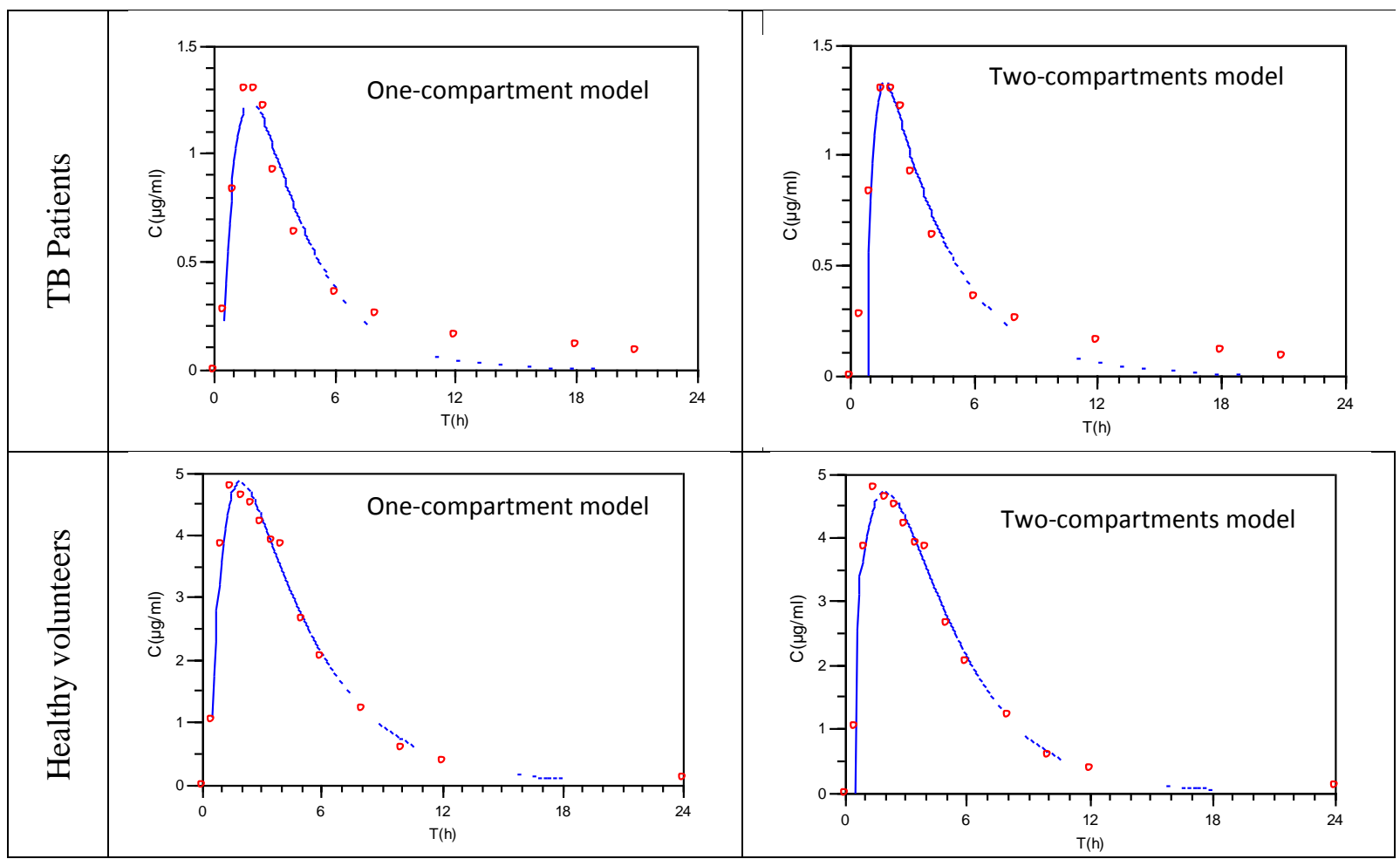

Figure 5. Compartmental analysis of RIF pharmacokinetics after oral administration to TB patients.

Application of mathematical information Akaike and Schwarz criteria indicated the monocompartmental model as being more performant than the bicompartmental one. In fact, this implies that improving the fitting by increasing the number of parameters is countered by a decrease of the stability in the parameters associated to models. Decreasing of the sum of errors towards the predicted curve was too low after increasing the number of compartments to justify the acceptance of the bicompartmental model.

Mean values and their standard deviations for all pharmacokinetics parameters are shown in Table 1.

Table 1. Pharmacokinetic parameters of RIF after oral administration to TB patients $(n=12)$ and healthy volunteers $(n=54)$

\begin{tabular}{||l||c|c|c||c|c|c||}
\hline \hline \multirow{2}{*}{\multicolumn{1}{|c||}{ Parameter }} & \multicolumn{3}{c||}{ Healthy volunteers } & \multicolumn{3}{c||}{ TB patients } \\
\cline { 2 - 7 } & Mean & Stdev & $\% C V$ & Mean & Stdev & $\%$ CV \\
\cline { 2 - 7 } & 5.85 & 2.71 & 46.27 & 1.78 & 1.41 & 79.37 \\
\hline $\mathrm{C}_{\max }(\mu \mathrm{g} / \mathrm{ml})$ & 26.21 & 10.70 & 40.81 & 6.90 & 5.42 & 78.56 \\
\hline $\mathrm{AUC}_{0-24}(\mu \mathrm{g} / \mathrm{ml} * \mathrm{~h})$ & 27.43 & 11.44 & 41.69 & 7.73 & 5.24 & 67.87 \\
\hline $\mathrm{AUC}_{\text {tot }}\left(\mu \mathrm{g} / \mathrm{ml}{ }^{*} \mathrm{~h}\right)$ & 1.94 & 1.03 & 53.13 & 2.00 & 0.60 & 30.15 \\
\hline Tmax $(\mathrm{h})$ & 2.23 & 0.62 & 27.57 & 5.42 & 3.86 & 50.87 \\
\hline thalf $(\mathrm{h})$ & 0.34 & 0.11 & 32.31 & 0.12 & 0.06 & 53.18 \\
\hline Ke $\left(\mathrm{h}^{-1}\right)$ & 13.78 & 12.36 & 89.68 & 26.80 & 15.27 & 56.97 \\
\hline Clearance $(1 / \mathrm{h})$ & & & & &
\end{tabular}

\section{Discussions}

High variability of the pharmacokinetics in patients seems to be the rule in the case of main tuberculostatic drugs. For example, it was reported that plasma concentration-time profiles not only for RIF, but also for Isoniazid, Pyrazinamide, and Ethambutol in 142 patients with drug-sensitive pulmonary tuberculosis after 2 months of daily treatment in hospital were highly variable (MCILLERON, 2006). 
In the case of patients with both tuberculosis and diabetes appears a supplementary factor contributing to variability - the weight of patients (NIEMI, 2000). Some studies have shown the effect of body weight (ZVADA, 2014). The reduced exposure to RIF of diabetic patients in the continuation phase may be due to increased body weight and possible differences in hepatic induction. These conclusions are most probable applicable in comparison healthy volunteers and tuberculosis patients: a decrease of plasma levels following an increase of body weight (WILKINS, 2008).

Physiopathological conditions and genetic polymorphism are other factors of variability. Patients with mild or moderate renal failure (creatinine clearance: $10.1-50.0 \mathrm{ml} / \mathrm{min}$ ) and patients with severe renal failure (creatinine clearance $<10.0 \mathrm{ml} / \mathrm{min}$ ) were compared with healthy subjects (SOUSA, 2008). The renal excretion of Isoniazid, Acetyl isoniazid, RIF and Desacetyl-rifampicin was severely inhibited in patients with renal failure. Plasma RIF and Isoniazid concentrations in rapid acetylators were similar in healthy subjects and both the groups of patients.

Low RIF bioavailability was attributed to several factors including malabsorption, increased hepatic clearance due to autoinduction, enhanced intestinal metabolism and drug interactions (AGRAWAL, 2005; GRANGE, 1994; LOOS, 1985).

In patients with multidrug-resistant tuberculosis (MDR-TB), drug susceptible tuberculosis (DS-TB), and healthy volunteers, peak serum concentrations of RIF were significantly lower in MDR-TB and DS-TB as compared with healthy volunteers (BARROSO, 2009).

A comparison of mean pharmacokinetic parameters measuring exposure (area under the concentration-time curve of the drug in plasma from 0 to $6 \mathrm{~h}$ post dose) and the mean peak concentration in plasma $\left(\mathrm{C}_{\max }\right)$ of $\mathrm{RIF}$ in tuberculosis with and without type 2 diabetes put in evidence that these parameters were 2 -fold lower in patients with diabetes than in those without diabetes (NIJLAND, 2006).

Comparison of RIF exposure after oral and intravenous administration showed that no differences in the areas AUC curves of the drugs in plasma from 0 to $24 \mathrm{~h}$ post dose $\left(\mathrm{AUC}_{0-24}\right)$, the maximum concentrations of the drugs in plasma $\left(\mathrm{C}_{\max }\right)$, the time to maximum concentration (Tmax), and the half-live of RIF, pyrazinamide, and ethambutol were found between diabetic and nondiabetic tuberculosis patients in the intensive phase of tuberculosis treatment (RUSLAMI, 2010).

In conclusion, the variability of the pharmacokinetics in patients, much greater than that of healthy volunteers observed in our study is more or less an expected result. Since patients were newly diagnosed and immediately treated with RIF, it is most probable that an associated co-morbidity, more or less evident, to be present.

It is also to underline that data in literature concerns pharmacokinetics after repeated doses, when additional modification appears in time for both healthy subjects and patients.

Partition into two clusters of the population of plasma level curves of patients could be the consequence of partition in patients with only TB and patients with TB and other diseases which influence the pharmacokinetics of RIF even from the beginning of treatment.

Examination of mean curves suggests a more refinement analysis for differences between pharmacokinetics of healthy subjects and patients. Final parts of mean curves $(12 \mathrm{~h}-24 \mathrm{~h})$ for healthy subjects and patients are practically superposed. Differences appeared in the time interval from $\mathrm{T}_{\max }$ and 12 hours, following a superposition of a distribution and an elimination process. In the same time, the metabolism is expected to be more extensive in the intermediary phase that in the final one.

All these results suggest the necessity of increasing the doses of RIF, at least at the beginning of treatment. Administration of sub-therapeutic doses in tuberculosis may contribute towards the development of drug resistance (DENHOLM, 2010). A recent review and meta-analysis, based on almost all studies published before 2018, concludes this for entire treatment interval (STOTT, 2018).

Compartmental analysis. When applying compartmental mathematical modelling, we somewhat unexpectedly obtained that the monocompartmental model fits well enough the experimental data. Since RIF has a high partition coefficient $(\log \mathrm{P}=2,7)(\mathrm{VARMA}, 2012)$ its distribution in lipid compartment and its metabolism have to be significant. But, as was previously found (MARCHIDANU, 2013) concentration of metabolite in plasma is much smaller than that of RIF. This not a singular case when mathematical and statistical criteria lead to different models that those expected based on physicochemical and physiological criteria (SANDULOVICI, 2009). Choice and validation of theoretical models have to be the result of both type of analysis (PRASACU, 2009). More difficult is the interpretation of differences between intensive parameters: half-time ( $\left.\mathrm{t}_{\text {half }}\right)$ and distribution volume.

But beyond explanations remain the possibility of predicting pharmacokinetics, using the simplest model, both in case of healthy subjects and patients.

Low power studies. It is important to underline that conclusions in case of patients, following the small number of individual pharmacokinetic profiles are not certitudes. The problem of the adequate size is disputed in literature but it is to underlined that it is worthy to publish small size clinical trials since the ulterior metanalysis can pool all together and better valuate the individual results (MANOLACHE, 2017).

\section{Conclusions}

1. Variability of pharmacokinetics of RIF was high both in patients and healthy subjects the distribution of curves in patients being less homogenous than in healthy subjects.

2. Mean concentration and area under curves in patients were smaller that in healthy volunteers but the phenomenon seems to be more complex since there were also healthy subjects with lower concentrations than levels in almost patients.

3. Practically in al cases maximum concentrations of patients were above $1 \mu \mathrm{g} / \mathrm{ml}$, the minimum therapeutic 
level. But this level was maintained less than three hours which suggests the necessity of increasing first administered doses, until a loading of compartments and saturation of elimination processes.

4. Compartmental analysis indicated a very simple monocompartmental model for evolution of plasma levels in practically all cases. Models failed in fitting well the tail concentrations. Increasing the number of compartments couldn't solve these problems.

5. Pharmacokinetics of RIF is influenced by absorption, metabolism and renal elimination. Consequently, associated diseases affecting liver and renal functions have to significantly modify plasma profiles. Further studies are needed to verify the findings in case of patients with different associated diseases.

\section{References}

1. ABULFATHI AA, DECLOEDT EH, SVENSSON EM, DIACON AH et al. Clinical Pharmacokinetics and Pharmacodynamics of RIF in Human Tuberculosis. Clin Pharmacokinet. 2019; 58(9): 11031129. doi: 10.1007/s40262-019-00764-2

2. AGRAWAL S, PANCHAGNULA R. Implication of biopharmaceutics and pharmacokinetics of RIF in variable bioavailability from solid oral dosage forms. Biopharm. Drug Dispos. 2005; 26(8): 321-334.

3. ALMAHDAWY OT, PRICOP R, SADIK O, NAJEE H, PIRCALABIORU G, MARUTESCU L, BARBU I, BANU O, CRISTEA V, GRIGORE R, GHEORGHE I, MIHAESCU G. Description of vancomycin resistance genes in Enterococcus sp. clinical strains isolated from Bucharest, Romania. Rom Biotechnol Lett. 2019; 24(3): 395-399. DOI: $10.25083 / \mathrm{rbl} / 24.3 / 395.399$

4. BAICUS A, LIXANDRU B, STROIA M, CIRSTOIU M, CONSTANTIN A, USEIN C , CIRSTOIU CF, Antimicrobial susceptibility and molecular epidemiology of carbapenem-resistant Klebsiella pneumoniae strains isolated in an emergency university hospital, Romanian Biotechnological Letters, vol. 23, no. 2, 2018, 13525-9.

5. BARROSO EC, PINHEIRO VG, FAÇANHA MC, CARVALHO MR et al. Serum concentrations of rifampin, isoniazid, and intestinal absorption, permeability in patients with multidrug resistant tuberculosis. The American journal of tropical medicine and hygiene. 2009; 81(2): 322-329.

6. BRAYFIELD A. ed. Martindale: the complete drug reference. 39th ed. Pharmaceutical Press. London. 326-329. 2017.

7. DENHOLM JT, MCBRYDE ES. The use of antituberculosis therapy for latent $\mathrm{TB}$ infection. Infect Drug Resist. 2010; 3: 63.

8. ELLARD G, FOURIE P. RIF bioavailability: a review of its pharmacology and the chemotherapeutic necessity for ensuring optimal absorption. The International Journal of Tuberculosis and Lung Disease. 1999; 3(11): S301-S308.

9. FDA. Guidance for industry: bioanalytical method validation. Food and Drug Administration - Center for Drug Evaluation and Research (CDER)/ Center for Veterinary Medicine (CVM): Rockville, MD, USA. 2001. Available from address: http://www.fda.gov/Drugs/GuidanceComplianceRegu latoryInformation/Guidances/default.htm

10. GLAESER H, DRESCHER S, EICHELBAUM M, FROMM M. Influence of RIF on the expression and function of human intestinal cytochrome P450 enzymes. Br. J. Clin. Pharmacol. 2005; 59(2): 199-206.

11. GRANGE JM, WINSTANLEY PA, DAVIES PD. Clinically significant drug interactions with antituberculosis agents. Drug Saf. 1994; 11(4): 242-251.

12. LOOS U, MUSCH E, JENSEN JC, MIKUS G et al. Pharmacokinetics of oral and intravenous RIF during chronic administration. Klin. Wochenschr. 1985; 63(23): 1205-11. doi: 10.1007/bf01733779.

13. MANOLACHE M, MIRCIOIU C, MIRCIOIU I, PRASACU I et al. Phenomenological and Mathematical Evaluation of Aberrant Values (Outliers) in Bioequivalence Studies. Journal of Applied Biopharmaceutics and Pharmacokinetics. 2017; 5: 19-25.

14. MARCHIDANU D, RADUCANU N, MIRON DS, RADULESCU FS et al. Comparative pharmacokinetics of RIF and 25-desacetyl RIF in healthy volunteers after single oral dose administration. FARMACIA. 2013; 61(2): 398-410.

15. MCILLERON H, WASH P, BURGER A, NORMAN $\mathrm{J}$ et al. Determinants of rifampin, isoniazid, pyrazinamide, and ethambutol pharmacokinetics in a cohort of tuberculosis patients. Antimicrobial agents and chemotherapy. 2006; 50(4): 1170-1177.

16. MEDELLÍN-GARIBAY S, CORTEZ-ESPINOSA N, MILÁN-SEGOVIA R, MAGAÑA-AQUINO $M$ et al. Clinical pharmacokinetics of rifampin in patients with tuberculosis and type 2 diabetes mellitus: association with biochemical and immunological parameters. Antimicrob. Agents Chemother. 2015; 59(12): 77077714.

17. MILAN-SEGOVIA R, DOMINGUEZ-RAMIREZ A, JUNG-COOK H, MAGANA-AQUINO $M$ et al. Relative bioavailability of RIF in a three-drug fixeddose combination formulation. The International Journal of Tuberculosis and Lung Disease. 2010; 14(11): 1454-1460.

18. MIRCIOIU C, IONICA G, DANILCEAC A, MIRON $\mathrm{D}$ et al. Pharmacokinetic and mathematical outliers for drugs with active metabolites. Note I. Model independent analyses for pentoxifylline. FARMACIA. 2010; 58(3): 264-278.

19. NIEMI M, KIVISTO KT, BACKMAN JT, NEUVONEN PJ. Effect of RIF on the pharmacokinetics and pharmacodynamics of glimepiride. Br J Clin Pharmacol. 2000; 50(6): 591-5. doi: 10.1046/j.1365-2125.2000.00295.x.

20. NIJLAND HM, RUSLAMI R, STALENHOEF JE, NELWAN EJ et al. Exposure to RIF is strongly reduced in patients with tuberculosis and type 2 diabetes. Clin. Infect. Dis. 2006; 43(7): 848-854. 
21. PÄHKLA R, LAMBERT J, ANSKO P, WINSTANLEY $P$ et al. Comparative bioavailability of three different preparations of RIF. J. Clin. Pharm. Ther. 1999; 24(3): 219-225.

22. PANCHAGNULA R, RUNGTA S, SANCHETI P, Agrawal $S$ et al. In vitro evaluation of food effect on the bioavailability of RIF from antituberculosis fixed dose combination formulations. Il Farmaco. 2003; 58(11): 1099-1103.

23. PARGAL A, RANI S. Non-linear pharmacokinetics of RIF in healthy Asian Indian volunteers. The International Journal of Tuberculosis and Lung Disease. 2001; 5(1): 70-79.

24. PELOQUIN CA, NAMDAR R, SINGLETON MD, NIX DE. Pharmacokinetics of rifampin under fasting conditions, with food, and with antacids. Chest. 1999; 115(1): 12-18.

25. PRASACU I, MIRCIOIU C, SANDULOVICI R, ENACHE F. Release of metoprolol from solid dosage forms. Choice and validation of theoretical model. Farmacia. 2009; 1: 89-98

26. RAFIQ S, IQBAL T, JAMIL A, KHAN FH. Pharmacokinetic studies of RIF in healthy volunteers and tuberculosis patients. Int. J. Agric. Biol. 2010; 12: 391-5.

27. RAMAKRISHNAN K, SHENBAGARATHAI R, KAVITHA K, UMA A et al. Serum zinc and albumin levels in pulmonary tuberculosis patients with and without HIV. Japanese Journal of Infectious Disease. 2008; 61(3): 202-204.

28. REQUENA-MENDEZ A, DAVIES G, WATERHOUSE D, ARDREY A et al. Intra-individual effects of food upon the pharmacokinetics of RIF and isoniazid. J. Antimicrob. Chemother. 2019; 74(2): 416424. doi: 10.1093/jac/dky444.

29. RUSLAMI R, NIJLAND HM, ADHIARTA IGN, KARIADI SH et al. Pharmacokinetics of antituberculosis drugs in pulmonary tuberculosis patients with type 2 diabetes. Antimicrob. Agents Chemother. 2010; 54(3): 1068-1074.

30. SANDULOVICI R, PRASACU I, MIRCIOIU C, VOICU V et al. Mathematical and phenomenological criteria in selection of pharmacokinetic model for M1 metabolite of pentoxyphylline. Farmacia. 2009; 57(2): 235-247.

31. SEIJGER C, HOEFSLOOT W, BERGSMA-de GUCHTENEIRE I, TE BRAKE L et al. High-dose RIF in tuberculosis: Experiences from a Dutch tuberculosis centre. PLoS One. 2019; 14(3): e0213718.

32. SENG KY, HEE KH, SOON GH, CHEW N et al. Population pharmacokinetics of RIF and 25-deacetylRIF in healthy Asian adults. J Antimicrob Chemother. 2015; 70(12): 3298-306. doi: 10.1093/jac/dkv268.
33. SOUSA M, POZNIAK A, BOFFITO M. Pharmacokinetics and pharmacodynamics of drug interactions involving RIF, rifabutin and antimalarial drugs. Journal of Antimicrobial Chemotherapy. 2008; 62(5): 872-878.

34. STOTT K, PERTINEZ H, STURKENBOOM M, BOEREE $M$ et al. Pharmacokinetics of RIF in adult TB patients and healthy volunteers: a systematic review and meta-analysis. J. Antimicrob. Chemother. 2018; 73(9): 2305-2313.

35. STOTT KE, PERTINEZ H, STURKENBOOM MGG, BOEREE MJ et al. Pharmacokinetics of RIF in adult TB patients and healthy volunteers: a systematic review and meta-analysis. J Antimicrob Chemother. 2018; 73(9): 2305-2313. doi: 10.1093/jac/dky152.

36. SUDFELD CR, ISANAKA S, ABOUD S, MUGUSI FM et al. Association of serum albumin concentration with mortality, morbidity, CD4 T-cell reconstitution among tanzanians initiating antiretroviral therapy. The Journal of Infectious Diseases. 2013; 207(9): 1370-1378.

37. SVENSSON RJ, AARNOUTSE RE, DIACON AH, DAWSON R et al. A Population Pharmacokinetic Model Incorporating Saturable Pharmacokinetics and Autoinduction for High RIF Doses. Clin Pharmacol Ther. 2018; 103(4): 674-683. doi: 10.1002/cpt.778.

38. SVENSSON RJ, AARNOUTSE RE, DIACON AH, DAWSON R et al. A population pharmacokinetic model incorporating saturable pharmacokinetics and autoinduction for high RIF doses. Clin. Pharmacol. Ther. 2018; 103(4): 674-683.

39. VARMA MV, LAI Y, FENG B, LITCHFIELD J et al. Physiologically based modeling of pravastatin transporter-mediated hepatobiliary disposition and drugdrug interactions. Pharm. Res. 2012; 29(10): 2860-2873.

40. WILKINS JJ, SAVIC RM, KARLSSON MO, LANGDON G et al. Population pharmacokinetics of rifampin in pulmonary tuberculosis patients, including a semimechanistic model to describe variable absorption. Antimicrobial agents and chemotherapy. 2008; 52(6): 2138-2148.

41. ZENT C, SMITH P. Study of the effect of concomitant food on the bioavailability of RIF, isoniazid and pyrazinamide. Tuber. Lung Dis. 1995; 76(2): 109-113.

42. ZVADA SP, DENTI P, DONALD PR, SCHAAF HS et al. Population pharmacokinetics of RIF, pyrazinamide and isoniazid in children with tuberculosis: in silico evaluation of currently recommended doses. J Antimicrob Chemother. 2014; 69(5): 1339-49. doi: 10.1093/jac/dkt524.

43. ZWOLSKA Z, AUGUSTYNOWICZ-KOPEC E, NIEMIROWSKA-MIKULSKA H. The pharmacokinetic factors and bioavailability of RIF, isoniazid and pyrazinamid fixed in one dose capsule. Acta Pol. Pharm. 2002; 59(6): 448-451. 